\title{
El futuro de la seguridad y la defensa en la UE post-Brexit: el salto a la integración
}

\author{
The Future of Security and Defence in the EU Post-Brexit: \\ the Leap to Integration
}

\author{
José Luis de Castro Ruano \\ Profesor Titular de Relaciones Internacionales UPV/EHU y Cátedra Jean Monnet, \\ joseluis.decastro@ehu.eus \\ Diego Borrajo Valiña \\ Investigador postdoctoral UPV/EHU \\ diego.borrajo@ehu.eus
}

Sumario: I. Introducción. La paradógica parálisis post-Lisboa. - II. La «policrisis» de la U.E. como factor de profundización del proceso de integración.-III. Tres escenarios para la seguridad y defensa en la UE: el informe de la comisión.-IV. Nuevos desarrollos de la PCSD: hacia una unión de la seguridad y la defensa.-V. El Reino Unido y la defensa comunitaria tras el Brexit: la iniciativa europea de intervención.-VI. Conclusiones.-VII. Bibliografía.

Resumen: En este trabajo analizamos los últimos desarrollos que en la Unión Europea se están llevando a cabo en materia de seguridad y defensa; y reflexionamos en torno a la evolución de este ámbito en la UE post-brexit. Paradójicamente, desde el momento de la celebración del referéndum británico para el abandono de la Unión en 2016, la UE ha tomado numerosas e innovadoras iniciativas en materia de seguridad y defensa que, aunque eran contempladas en el Tratado de Lisboa, no habían podido materializarse precisamente por la oposición británica. La relevancia de estas iniciativas nos lleva a aventurar que estamos en los albores del surgimiento de una Unión de la Seguridad y la Defensa que implica el salto a la integración en un ámbito de especial relevancia como es el que nos ocupa.

Palabras clave: Política Común de Seguridad y Defensa; Seguridad y Defensa; Crisis; Brexit

Abstract: In this paper we analyse the latest developments in the European Union in terms of security and defence; and we reflect on the evolution of this field in the EU post-Brexit. Paradoxically, after the EU referendum in the UK for the abandonment of the Union in 2016, the EU has implemented 
many innovative initiatives in the field of security and defence which, although contemplated in the Treaty of Lisbon, had not been able to materialise precisely because of the British opposition. The relevance of these initiatives leads us to venture that we are in the dawn of the emergence of a Union of Security and Defence that implies the leap to integration in this area of special relevance that concerns us in this paper.

Keywords: Common Security and Defence Policy; Security and Defence; Crisis; Brexit

\section{Introducción. La paradógica parálisis post-Lisboa}

Aunque la seguridad y la defensa fueran ajenas a las Comunidades Europeas en sus tratados constitutivos, la búsqueda de instrumentos específicamente comunitarios en esta materia estuvo en el «entorno» del proceso de integración. La Seguridad haría su entrada en los Tratados, aunque de forma muy tímida, con la reforma del Acta Única Europea en el marco de la Cooperación Política Europea ${ }^{1}$. La ruptura de la bipolaridad y la caída del muro de Berlín favorecieron el cambio cualitativo desde una Comunidad económica a la Unión de naturaleza política, con el establecimiento de la Política Exterior y de Seguridad Común - PESC - en el Tratado de Maastricht de 1993 como uno de sus ingredientes más notables. La incapacidad comunitaria para enfrentar las crisis de los Balcanes impulsó la creación de la Política Europea de Seguridad y Defensa - PESD - . Desde 2003 hasta hoy la Unión ha desarrollado más de una treintena de misiones operativas de naturaleza civil y militar a lo largo del mundo.

Durante estos años la Unión ha mostrado una cierta capacidad de intervención en diferentes episodios de resolución de conflictos y gestión de crisis. Por lo general han sido crisis relativamente modestas, mayoritariamente en procesos postconflicto, algunas veces dando continuidad a intervenciones «duras» de la OTAN o en apoyo a Misiones de Naciones Unidas u otras organizaciones como la Unión Africana, para enfrentar situaciones en que era necesario establecer unas mínimas condiciones de seguridad. Además, la UE ha llevado a cabo una serie de misiones civiles de

${ }^{1}$ Referida únicamente a los aspectos políticos y económicos de la misma. El artículo 30.6 del AUE establece que «una cooperación más estrecha en las cuestiones de seguridad europea podrá contribuir de manera esencial al desarrollo de una identidad europea en materia de política exterior» para lo que manifiesta su disposición a una mayor coordinación de «los aspectos políticos y económicos de la seguridad». 
fortalecimiento del Estado de Derecho; misiones de policía y reforma del sector de la seguridad; misiones de observación; misiones de asistencia fronteriza; misiones de administración civil de territorios; así como una cantidad importante de misiones de protección civil y de asistencia humanitaria de diverso tipo ${ }^{2}$. Evidentemente no estábamos preparados para crisis potentes, de gran complejidad y duración, como la de Afganistán o Irak, ante la cual la UE se fracturó internamente ${ }^{3}$. La PESD fue progresivamente convirtiéndose en un instrumento de intervención postconflicto y gestión de crisis, que nos ha permitido intervenir en aquellas crisis a la medida de nuestras capacidades y voluntad política, bienes bastante escasos ambos. Y algo, desde luego, alejado de lo que es exigible a un actor de la naturaleza y dimensión de la UE.

El Tratado de Lisboa daba un paso más con la transformación de la PESD en PCSD - Política Común de Seguridad y Defensa - incluyendo elementos que posibilitan una mayor y mejor presencia de la UE en el mundo ${ }^{4}$; instrumentos que, en concordancia con la siempre necesaria voluntad política de los Estados miembros ${ }^{5}$, permiten a la Unión desarrollar una acción exterior autónoma más ambiciosa para enfrentar crisis de mayor envergadura. Paradójicamente, tras la entrada en vigor del Tratado de Lisboa en 2009, empezaremos a observar un cierto anquilosamiento de la PCSD; precisamente cuando contábamos con más instrumentos políticos y jurídicos para actuar, y cuando asistíamos a una mayor demanda de seguridad en

2 Vid. GARCIA PÉREZ, R.; «Las misiones PESD como instrumento de la política exterior de la UE» en Cursos de Derecho Internacional y Relaciones Internacionales de Vitoria-Gasteiz, 2009. Leioa, Servicio Editorial de la UPV/EHU, 2010. Vid. también URIBE OTALORA, A.; La Política de Seguridad y Defensa de la Unión Europea. Las misiones en el exterior. Valencia, tirant lo blanch, 2014.

${ }^{3}$ BARBÉ, E.; «Las primeras víctimas de la crisis iraquí: el prestigio de Europa como actor internacional y la capacidad negociadora de España en el marco de la UE» en Revista General de Derecho Europeo, . $^{\circ}$ 1, 2003 (www.iustel.com).

4 Vid. DE CASTRO RUANO, J.L.; «Las nuevas capacidades de la UE en materia de política exterior en el Tratado de Lisboa» en Unión Europea. Aranzadi, Año XXXV, n. ${ }^{\circ} 10$, octubre de 2009.

${ }^{5}$ Como afirma Martin ORTEGA CARCELÉN, «los contenidos de esta política dependen de la voluntad de los Estados miembros, y la mera existencia de instrumentos mejores no supondrá necesariamente una política exterior más acabada», en «La Política Exterior y de Seguridad Común en el Tratado de Lisboa: un cauce adecuado a la espera de contenidos» en Cuadernos Europeos de Deusto, n. ${ }^{\circ}$ 40, 2009, p. 150. Mariola URREA se expresa en sentido semejante cuando afirma que el Tratado de Lisboa proporciona suficientes elementos a la PCSD para convertirse en una realidad perfectamente operativa, sin embargo «que así sea depende de la voluntad política de los Estados miembros para hacer efectiva la ambición que sobre la materia expresa la Unión»; en «La Política Común de Seguridad y Defensa en el Tratado de Lisboa: la eficacia como objetivo, la flexibilidad como instrumento y la ambición como propuesta», Revista Española de Derecho Europeo, n. . 33, 2010, p. 120. 
Europa, la PCSD se estancó ${ }^{6}$. Los instrumentos que el tratado de Lisboa había puesto a disposición para enfrentar mayores desafíos en materia de seguridad y defensa, no se activaron por una falta de ambición colectiva y de voluntad política que llevó a la Unión a mantenerse como un actor humanitario y de reconstrucción postconflicto, muy alejado de lo que se presume a un actor global según predica la retórica comunitarista ${ }^{7}$.

Indudablemente Lisboa mejora la regulación de la gestión de crisis, ampliando los casos en los que se justificaría una misión de la UE y, además, prevé la creación de instrumentos específicos en materia de seguridad y defensa. El artículo 42.2 no deja lugar a dudas acerca de la vocación de la PCSD de construir una defensa común europea «una vez que el Consejo Europeo lo haya decidido por unanimidad»; así: la cooperación para una misión(artículo 42.5), la cooperación estructurada permanente (artículo 42.6), la cooperación para la defensa mutua (artículo 42.7), los tipos de misiones previstas en el artículo 43, el reforzamiento jurídico de la Agencia Europea de Defensa (artículo 42.3) y las misiones concretas a ella asignadas (artículo 45).

El artículo 42.1 establece que la PCSD proporcionará una capacidad operativa para desarrollar misiones fuera de la Unión que tengan por objeto garantizar el mantenimiento de la paz, la prevención de conflictos y el fortalecimiento de la seguridad internacional, conforme a los principios de la Carta de las Naciones Unidas. Posteriormente, el artículo 43 establece, ampliándolas, los tipos de misiones susceptibles de ser desarrolladas en el ámbito de la PCSD.A las ya clásicas misiones humanitarias y de rescate, misiones de prevención de conflictos y de mantenimiento de la paz, misiones para la gestión de crisis en las que intervengan fuerzas de combate incluidas las misiones de restablecimiento de la paz así como las operaciones de estabilización al término de los conflictos (las Misiones Petersberg que

${ }^{6}$ Algunos hablaron incluso de «irrelevancia». Vid. YOUNGS, R.; Europe's decline and fall: the struggle against global irrelevance. London, Profile Books, 2010. Otros simplemente consideran que la PCSD «is the weakest link in the European integration project»; en AA.VV.; More Union in European Defense. Report of a CEPS Task Force. Brussels, Centre for European Policy Studies, 2015, p. 1.

${ }^{7}$ Incapaz de actuar incluso en crisis desatadas en entornos cercanos, como Libia. Sobre la inacción comunitaria en Libia vid. nuestro trabajo «La Unión Europea y la gestión de crisis: entre las potencialidades del Tratado de Lisboa y la falta de voluntad de los Estados: Libia como evidencia» en VÁZQUEZ GÓMEZ, E.M.; ADAM MUÑOZ, M.D.; CORNAGO PRIETO, N. (Coords.); El arreglo pacífico de controversias internacionales; Valencia, Tirant lo blanch, 2013. Otros lo expresan de forma descarnada como Hubert VÉDRIN: «On this occasion, European defense, for 30 years the object of so many proclamations, especially in France, was shown up for the illusion that it is: a hope that has become an empty Shell» en «The issue: When is it right to oust a tyrant? My veredict: in Libya it was justified, but it's an unsoung precedent», Europe's World, Autumn, 2011 (www.europesworld.org). 
recogía el Tratado de Niza en art. 17.2), se añaden misiones propias de la defensa: actuaciones conjuntas en materia de desarme, las misiones de asesoramiento, estabilización y de asistencia en cuestiones militares, así como de lucha contra el terrorismo.

El artículo 222 del TFUE se refiere a la Cláusula de Solidaridad, que se activará «si un Estado miembro es objeto de un ataque terrorista o víctima de una catástrofe natural o de origen humano». En estos casos, «La Unión movilizará todos los instrumentos de que disponga, incluidos los medios militares puestos a su disposición por los Estados miembros». Esta cláusula no es estricta ni exclusivamente defensiva, sino una obligación de solidaridad reforzada que abarca muchas otras dimensiones además de la propiamente militar: «(...) la Unión movilizará todos los instrumentos de que disponga, incluidos los medios militares $(\ldots) »^{8}$.

Lisboa, como hemos visto, amplía los tipos de misiones en el ámbito de la PCSD; sin embargo, el número de misiones operativas disminuyó. Del total de misiones desplegadas hasta el momento, 23 se pusieron en marcha antes del Tratado de Lisboa, es decir, entre el 2003 y el 2009; y desde entonces, y a pesar del robusto andamiaje jurídico que proporciona este Tratado, solo se desarrollaron diez nuevas, y de ellas únicamente cuatro de naturaleza militar: EUTM Somalia (2010), EUTM Mali (2013), EU NAVFOR Med (2015) y EUTM RCA (2016) (que sustituyó a la anterior EUMAN RCA). Ya durante el mandato de Mogherini se han lanzado las operaciones militares EUNAVFOR Med/Sophia (2015) y la EUTM RCA (2016) y las misiones civiles EUAM Ucrania (2014), EUCAP Sahel Mali (2015) (destinada a reforzar las capacidades policiales y judiciales en el país africano) y la última, la EUAM Irak (2017) para apoyar al gobierno iraquí en su reforma del sector civil de la seguridad (European Union Advisory Mission in support of Security Sector Reform in Iraq). Como la EUAM Ucrania, no se trata de una misión con mandato ejecutivo (de fuerza), sino una misión de asesoramiento. Como otras misiones de esta naturaleza, es de muy reducida dimensión: 51 personas en total, contados los 35 expertos europeos y el personal local; 14 millones de presupuesto anual (con cargo al presupuesto comunitario).

¿Es esta la dimensión esperada de las misiones/operaciones PCSD de un actor como la UE tras las potencialidades en seguridad y defensa que en-

8 ÁlVAREZ VERDUGO, M.; «Actores, procedimientos y capacidades de la Política Común de Seguridad y Defensa» en BARBÉ, E. (dir.); La Unión Europea en las relaciones internacionales, Madrid, Tecnos, 2014, p. 116. En sentido semejante se pronuncia GONZALEZ ALONSO, L.N.; «¿Obligación jurídica o mero compromiso político?: la cláusula de solidaridad en el Tratado Constitucional», en Revista General de Derecho Europeo, n. ${ }^{\circ}$ 12, 2007 (www.iustel.com). 
cierra el Tratado de Lisboa? Es obvio que en estos años post-Lisboa no se vieron satisfechas las expectativas que había generado el nuevo Tratado: hay unas capacidades de intervención en gestión internacional de crisis; un desarrollo institucional para la toma de decisiones en materia militar y unos mecanismos de generación de fuerzas; se llevaron a cabo una serie de misiones operativas de diferente envergadura (aunque nunca de una gran envergadura) en diferentes teatros de operaciones; pero con todo, los resultados fueron menores de los que cabía exigir a una organización internacional que reclama para sí un relevante protagonismo internacional.

Es obvio que no se habían satisfecho las expectativas que generó el Tratado de Lisboa con la inclusión de los instrumentos jurídicos y políticos señalados en las páginas anteriores. Es cierto que la coyuntura jugó en contra, pues la crisis financiera hizo girar los esfuerzos comunitarios hacia la superación de los problemas de la deuda soberana en la eurozona; las energías institucionales se volcaron a apuntalar la gobernanza del euro ante los riesgos inminentes (puesta en marcha de la Unión Bancaria, introducción de mejoras en la gobernanza financiera, etc.). Además, la crisis económica y la austeridad consiguiente detrajeron importantes recursos económicos. La crisis de liderazgo hizo el resto pues quien debía haber sido principal dinamizador «de la cosa», Catherine Ashton, bastante tuvo con la puesta en marcha del SEAE. Así las cosas, se requería un nuevo impulso que propiciara el relanzamiento?.

\section{La «policrisis» de la UE como factor de profundización del proceso de integración}

En la coyuntura actual la Unión Europea se encuentra en una situación inédita. Si bien no es la primera vez que el proceso de integración europea atraviesa una situación de crisis (es ya un tópico afirmar que la UE avanza en situaciones de crisis) sí es la primera vez que asistimos a una superposición de crisis de diferente naturaleza que, según algunos, amenazan la viabilidad y existencia del proyecto comunitario en su totalidad.

En mayo del 2005, los referéndums negativos en Francia y los Países Bajos, abortaban la reforma de los tratados que habría de haber alumbrado el Tratado constituciona ${ }^{10}$. La crisis institucional subsiguiente, y la paráli-

9 Vid. DE CASTRO RUANO, J.L.; «La evolución de la Unión Europea como actor en materia de seguridad y defensa. En busca de un relanzamiento siempre pendiente» en Cuadernos Europeos de Deusto, n. ${ }^{\circ}$ especial, octubre de 2015.

${ }^{10}$ En su denominación oficial: Tratado por el que se establece una Constitución para Europa. 
sis del proceso, se extendería hasta la aprobación del Tratado de Lisboa y su entrada en vigor en diciembre de 2009. En el 2008 importamos desde Estados Unidos una crisis financiera que, dada nuestra singular moneda única, el Euro, tuvo un efecto devastador. Esta crisis financiera mutó en 2010 en una singular crisis del euro y crisis de deuda cuyas consecuencias (las políticas de contención de gasto y de recortes sociales con que se intentó atajar) desembocaron a su vez en una crisis social que afectó con especial gravedad a algunos países y a algunos sectores de la población, disparando el paro y la exclusión. Todo ello generó a su vez una crisis política y de rechazo social hacia la UE. Los populismos de derecha (fundamentalmente) y de izquierda, y los partidos euroescépticos, cuando no abiertamente eurófobos, alcanzaron el poder en diferentes Estados (Italia, Austria, Polonia, Hungría, etc.). Los escaños ocupados por representantes políticos cuyo objetivo fundamental es acabar con el proceso de integración, fueron poblando el hemiciclo del Parlamento Europeo ${ }^{11}$. Para acrecentar más aún la crisis política, en 2015 estalló la crisis migratoria. Como consecuencia directa de las guerras de Siria y Libia, además de la multiplicidad de conflictos y crisis estructurales en diferentes países africanos, arriban al continente europeo importantes cantidades de inmigrantes económicos y demandantes de asilo que huyen de situaciones dramáticas en sus propios países. La situación se hace muy difícil de gestionar y las miradas críticas se dirigen, una vez más, a las instituciones comunitarias que se convierten en injustas paganas de una dramática falta de solidaridad y de justicia cuyos responsables no son sino los Estados europeos - y no la Unión Europea, precisamente-.

Por si todo esto no fuera ya suficiente, se superpondrá además una crisis institucional ignota como consecuencia del Brexit. Por primera vez en los más de sesenta años del proceso de integración europea, un país de-

11 En 1984 se crea por primera vez un grupo de extrema derecha en el PE, el denominado Grupo de las Derechas Europeas integrado por el Frente Nacional francés, el Movimiento Social Italiano, la Unión Política Nacional griega, etc. En la legislatura que ahora finaliza, hay dos grupos políticos que, aun siendo diferentes, se encuadran dentro de un populismo eurófobo de distinto signo. El Grupo Democracia Directa, con 43 escaños resultantes principalmente del partido de Bepe Grillo «5 Estrellas» (17 eurodiputados) y el Partido por la Independencia británico de Neil Farage (19 escaños) además de otros representantes de Lituania, la República Checa, Suecia, etc. Y el Grupo Europa de las Naciones y las Libertades, con 35 escaños provenientes del Vlams Belang flamenco, el Frente Nacional francés, el Partido de la Libertad de Austria FPO, la Liga Norte de Salvini, el Partido por la Libertad de Holanda de Geert Wilders, el Congreso Polaco de la Nueva Derecha y otros. Además, dentro de los No Inscritos nos encontramos con representantes del Movimiento por una Hungría Mejor Jobbik, la Aurora Dorada griega, el Partido Democrático Unionista de Irlanda del Norte, etc. Todo ello hace que se acerque a la centena el número de eurodiputados eurófobos en la legislatura que ahora termina. Si se unieran, podrían ser el tercer grupo político de la cámara en número de escaños. 
cidía abandonar. El Reino Unido decide en referéndum celebrado el 23 de junio de 2016 la salida de la Unión Europea y el artículo 50 del Tratado de Lisboa, se implementará por primera vez. La integración europea deja de ser un proceso unidireccional hacia más y más integración (deja de ser «una unión cada vez más estrecha entre los pueblos de Europa» como reza el artículo 1 del Tratado de la Unión Europea), para revertirse. Y en todo eso, Donald Trump alcanza la Casa Blanca sumiendo en una profunda crisis la fructífera relación transatlántica que habíamos tejido desde la Guerra Fría.

Y todo ello sin olvidar las diversas situaciones críticas de diversa naturaleza que se vienen produciendo en el vecindario de la UE en los últimos años: la Primavera árabe iniciada en 2011 provocará sucesivas crisis en diferentes países vecinos - y asociados a través de la Política Euromediterránea-; Rusia emerge cada vez más como un vecino desafiante y hostil (y no solo en Crimea y Ucrania, sino también penetrando en nuestras agendas políticas a través de insidiosas campañas de desinformación e intoxicación con intención desestabilizadora); la amenaza yihadista se hace presente con acciones terroristas que golpean reiteradamente en ciudades europeas, etc.

Esta situación, denominada por muchos como «policrisis», nos coloca ante un escenario incierto e imprevisible, que algunos consideraron como «crisis existencial» ${ }^{12}$. Sin embargo, el proceso de integración, lejos de naufragar y fracasar, se está reforzando más y más; la «policrisis» descrita anteriormente no solo no acaba con la UE sino que está llevando el proceso de integración a escenarios inéditos e impensables hasta hace bien poco; si bien, sí la transformará probablemente en una Unión a varias velocidades y círculos distintos, integración flexible y diferenciada, en la que no todos los socios compartirán las mismas políticas ni el mismo nivel de integración ni al mismo ritmo.

A pesar de las tendencias centrífugas (expresadas fundamentalmente por Reino Unido, por supuesto; pero sin olvidar la «disidencia comunitaria» y eurofobia creciente en diferentes Gobiernos de otros países como Polonia y Hungría, principalmente, aunque no solo: atentos a la evolución de Rumanía, Italia, etc.), se están dando también escenarios de profundización. La crisis del euro llevó a una profundización en la eurozona

12 Jean Claude Juncker no pudo ser más directo al inicio del Discurso sobre el Estado de la Unión de 2016 ante el Pleno del PE: «Hoy no me presento ante ustedes para decirles que todo va bien. No, no va bien. Seamos muy honestos en nuestro diagnóstico. Nuestra UE se encuentra, al menos en parte, en una crisis existencial» en Discurso sobre el Estado de la Unión «Hacia una Europa Mejor: una Europa que proteja, empodere y vele por la seguridad», 14 de septiembre de 2016. 
dotándonos de instrumentos supraestatales de gestión financiera y bancaria y avanzando hacia una Unión Bancaria y una Unión Monetaria aún incompletas (por ejemplo, sin Fondo Europeo de Garantía de Depósitos en el caso de la primera, y sin una unión fiscal, precondición para completar plenamente la segunda; próximos desafíos en este ámbito). La negociación del Brexit, paradójicamente, produce un cierre de filas y cohesión entre los socios comunitarios que dominan la partida negociadora al Reino Unido que se ve obligado a ceder una y otra vez en el proceso negociador, aceptando lo que, al inicio, no eran sino líneas rojas que afirmaba nunca traspasaría. Lo que en principio interpretamos como un gran problema, está convirtiéndose en una gran oportunidad, ya que el Reino Unido había obstaculizado el desarrollo de la Unión en clave federal especialmente en lo que se refiere a la consolidación del Modelo Social Europeo, el desarrollo de la Unión Económica y Monetaria, y en la puesta en marcha de una verdadera Política Común de Seguridad y Defensa. El Brexit permitirá retomar iniciativas de vocación federal paralizadas durante mucho tiempo ${ }^{13}$. Además, la amenaza terrorista que golpea una y otra vez a Europa, y la llegada de Donald Trump al poder, tienen como consecuencia superar un tabú histórico avanzando decididamente hacia la Unión de la Seguridad y la Defensa.

Así, nos encontramos con que las diferentes dimensiones de la crisis están teniendo el sorprendente y paradójico efecto de hacer profundizar el proceso de integración europea. El Brexit estaría revelándose como un federador interno y la llegada de Trump y el consiguiente debilitamiento de la relación transatlántica sería un federador externo. A pesar de padecer una situación como la descrita anteriormente, en los últimos dos años parece abrirse una ventana de oportunidad para avanzar en el proceso de integración llevando a cabo reformas de un calado impensable hace tan solo unos cuantos años ${ }^{14}$.

13 ALDECOA LUZARRAGA, F.; «La relevancia de la Agenda del relanzamiento europeo en el $60 .^{\circ}$ aniversario del Tratado de Roma y en $70 .^{\circ}$ del Congreso de Europa en La Haya»; en NASARRE, E., ALDECOA, F. y BENEDICTO, M.A. (coords). Europa como tarea. A los sesenta años de los Tratados de Roma y a los setenta del Congreso de Europa de la Haya. Madrid, Marcial Pons, 2018 p. 365

${ }^{14}$ El propio Juncker, en su Discurso sobre el Estado de la Unión del 2017 utilizaba un tono bien distinto al vislumbrar un escenario de posibilidades inéditas para avanzar: «(...) el viento vuele a henchir las velas de Europa. Se nos presenta ahora una oportunidad que no va a durar eternamente. Aprovechemos este impulso, aprovechemos los vientos favorables» para concluir que «Hemos empezado a arreglar el tejado. Y toca rematar la faena, ahora que el tiempo es favorable y mientras lo siga siendo. Porque cuando las próximas nubes aparezcan en el horizonte - y aparecerán - será demasiado tarde. Así que larguemos amarras. Zarpemos del puerto. Y aprovechemos los vientos alisios». 
Con todo, el escenario que se avecina es complicado e incierto. La UE se enfrenta a una pugna existencial, un desafío ontológico desde diferentes modelos protagonizados por los defensores de una Europa cosmopolita y liberal (aún con diferentes perfiles ideológicos, claro está, sea socialdemocracia, cristianodemócrata, etc.); y aquellos que propugnan un nacionalismo populista y xenófobo, expresiones de democracias iliberales ${ }^{15}$ que desde hace unos años, vienen ganando terreno en sucesivas elecciones estatales (Polonia y Hungría, por supuesto, pero también peligroso ascenso en la República Checa, Austria, Italia, Suecia, etc.) y amenazan las previsiones de las próximas euroelecciones a celebrar en 2019 con consecuencias potencialmente imprevisibles.

El impacto social de la gestión política de la crisis financiera, generó incertidumbre y dudas existenciales respecto a la viabilidad de la Unión Europea en su totalidad. Creció el desasosiego sobre el futuro de la UE. Así, en marzo de 2017, para animar la reflexión en torno al porvenir de la Unión en una coyuntura tan crítica, la Comisión Europea publicó el Libro Blanco sobre el futuro de Europa. Reflexiones y escenarios para la UE 27 en $2025^{16}$, enriquecido además con sucesivos documentos sectoriales sobre la dimensión social, el encauzamiento de la globalización, la profundización de la Unión Económica y Monetaria y el futuro de las finanzas y el futuro de la defensa europea, publicado en último lugar, el 7 de junio y al que luego nos referiremos específicamente. El Libro Blanco dibujaba cinco escenarios prospectivos; sucintamente: 1) seguir como hasta ahora, continuidad; 2) una Unión limitada al mercado único; 3) una Unión a diferentes velocidades en la que avanzarán más en la integración quienes más quieren, permitiendo una colaboración más estrecha en ámbitos específicos para algunos Estados («Los que deseen hacer más, hacen más»); 4) una Unión contenida caracterizada más por la cualidad que por la cantidad, limitada a menos integración pero más eficaz; es decir «hacer me-

15 Nos referimos con el término a esas democracias poco respetuosas con el Estado de derecho y las libertades individuales, tales como las que protagonizan gobiernos como el de Rodrigo Duterte en Filipinas, Nicolas Maduro en Venezuela, Donald Trump en Estados Unidos, Vladimir Putin en Rusia; pero también Viktor Orban en Hungría, o Jarowlaw Kaczynski en Polonia, etc. En todos estos ejemplos asistimos a expresiones de democracia formal, en la que se limitan peligrosamente más y más los elementos de control al poder político y de restricción a los gobernantes que existen en cualquier democracia consolidada. Vid. TAMAMES, J., «¿Es la democracia iliberal un problema?», Estudios de Política Exterior, 18 de abril de 2018 (https://politicaexterior.com). ZAKARIA, F., El futuro de la libertad: las democracias «iliberales» en el mundo. Madrid, Taurus, 2003.

${ }^{16}$ Comisión Europea, COM (2017), Libro Blanco sobre el futuro de Europa. Reflexiones y escenarios para la UE en 2025. 
nos pero de forma más eficiente» (aumentar las realizaciones en determinados ámbitos, reduciendo la intervención en los demás) y 5) el escenario más ambicioso que implica decididamente más integración hacia una Europa federal («hacer más conjuntamente en todos los ámbitos políticos»). El documento no establecía preferencia alguna por ninguno de los cinco escenarios propuestos.

En la conmemoración del 60 aniversario de la firma del Tratado de Roma de 1957, en marzo del 2017 y también en la capital italiana, los 27 (es decir, exceptuando al Reino Unido cuyo futuro se empieza a visualizar ya al margen de la familia comunitaria europea) rubricarán la Declaración de Roma reafirmando la vigencia y validez del proyecto de integración europea.

\section{Tres escenarios para la seguridad y la defensa en la UE: el informe de la Comisión}

Como hemos dicho anteriormente, el Libro Blanco sobre el Futuro de Europa se completaba con otros documentos sectoriales. Nosotros nos detendremos ahora en el análisis de uno de esos documentos, concretamente en el que se refiere al futuro de la Defensa europea ${ }^{17}$.

En este Documento se esbozan las grandes tendencias y retos para la seguridad y la defensa de la Unión de aquí a 2025, a la vez que se presentan diferentes opciones en el marco de tres escenarios diferentes para avanzar hacia una Unión de Seguridad y Defensa. Cada uno de estos tres escenarios propuestos, aunque no son exhaustivos ni se excluyen mutuamente, implica un diferente nivel de ambición a la hora de avanzar conjuntamente en materia de seguridad y defensa. De acuerdo con la Alta Representante Mogherini en el Prólogo del documento, partiendo de los avances registrados hasta la fecha en este ámbito, «ha llegado el momento de considerar cuál es el papel concreto que la Unión aspira a desempeñar en el futuro en materia de seguridad y defensa» ${ }^{18}$.Este Documento es la contribución de la Comisión a este debate.

La Comisión parte del principio de que, en el mundo de hoy, en el que la paz y la seguridad interior no pueden darse por sentadas dada la proliferación de nuevos tipos de amenazas, la seguridad y la defensa han de ocupar más espacio en el proyecto de integración europeo. Esto no significa la conversión de la Unión en una potencia militar; ésta, fundamentalmente

17 Vid. Documento de reflexión sobre el futuro de la defensa europea; Comisión Europea, COM (2017) 315 de 7 de junio de 2017.

18 Ibidem p. 3. 
seguirá siendo una potencia normativa cuyo principal activo consiste, precisamente, en su capacidad para establecer normas internacionales consecuencia de su protagonismo y posición de vanguardia en la gobernanza mundial (sea en el ámbito de la protección de los derechos humanos, cambio climático y medio ambiente, cooperación al desarrollo, sistema de $\mathrm{Na}$ ciones Unidas, etc.). Es su dimensión de poder blando (diplomacia, cooperación al desarrollo, comercio, etc.) su principal activo para la prevención de conflictos; pero en un mundo tan inestable como el actual, este poder blando ha de ser complementado con instrumentos duros de seguridad y defensa. Así, uno de los puntos fuertes de la UE es su capacidad para combinar poder duro y poder blando ${ }^{19}$.Como señaló el Presidente Juncker en sus Orientaciones Políticas de la Comisión Europea, el 15 de julio de 2014, Europa es esencialmente una «potencia suave». Pero ni las más sólidas de esas potencias pueden funcionar a largo plazo sin algunas capacidades de defensa integradas.

Según la Comisión, asistimos a una serie de factores estratégicos, políticos, económicos y tecnológicos que obligan a la UE a cambiar el rumbo en el ámbito de la seguridad y la defensa. Para alcanzar una Unión Europea de Seguridad y Defensa es necesario contar con una mayor cooperación en este ámbito; proceder a una armonización de las culturas estratégicas así como una visión común de las amenazas que nos acechan y las respuestas apropiadas; asumir más responsabilidades en nuestra propia seguridad dado que la relación transatlántica está cambiando y en el futuro no podremos contar tanto con EEUU; incrementar el volumen del gasto en defensa, pero también su eficiencia evitando duplicidades que afectan a la necesaria interoperabilidad; y por último, construir un verdadero mercado único de la defensa, aprovechando las economías de escala y la especialización por países ${ }^{20}$.

Así, en función de la voluntad política que muestren los Estados miembros para avanzar en este ámbito, según la Comisión, cabe contemplar tres escenarios posibles de cara al 2025; bien entendido que todos ellos constituyen pasos progresivos en la misma dirección ${ }^{21}$ :

a) Cooperación en materia de seguridad y defensa: en este escenario, los 27 miembros de la UE protagonizarían más cooperación en materia de seguridad y defensa que en el pasado; pero de forma voluntaria y caso por caso, sin ningún tipo de vinculación jurídica ni política, según surja una amenaza o una necesidad. La UE

19 Ibidem p. 6.

${ }^{20}$ Ibidem p. 11

${ }^{21}$ Ibidem p. 12 y ss. 
seguiría desarrollando misiones operativas civiles y militares de pequeña escala y de gestión de crisis, más o menos como las que realiza hasta la fecha. La UE complementaría los esfuerzos de los distintos Estados miembros y de nuestros principales aliados; seguiría intensificándose la cooperación con la OTAN en ámbitos como las amenazas hibridas, la ciberseguridad, la seguridad marítima, etc. La cooperación en defensa seguiría siendo un objetivo político; sin embargo, el sector europeo de la defensa seguiría estando fragmentado y el grueso de las capacidades de defensa seguirían siendo desarrolladas y contratadas a nivel nacional. Las acciones de seguridad y defensa de la UE seguirían dependiendo de contribuciones nacionales de carácter voluntario, lo que limitaría la capacidad de la UE a la hora de participar en las misiones más exigentes ${ }^{22}$.

b) Seguridad y defensa compartida: escenario más ambicioso que el anterior en el que los Estados comparten determinados activos financieros y operativos aumentando su solidaridad en la defensa y asumiendo un papel más importante en ámbitos como la ciberseguridad, la protección de fronteras, la lucha contra el terrorismo, desarrollando misiones y operaciones de más intensidad, con estructuras de gestión de crisis más eficaces y toma de decisiones más rápida. La UE reforzaría su capacidad de proyectar su poder militar y participar plenamente en la gestión de crisis externas y defensa de sus socios. Aumentaría su capacidad de proteger a Europa en ámbitos tales como la lucha contra el terrorismo, la respuesta a las amenazas híbridas o cibernéticas, el control de las fronteras o la seguridad marítima y energética. La UE cooperaría aún más con la OTAN. En lo tocante a la gestión de crisis, la UE reforzaría considerablemente su capacidad para proyectar fuerza militar al exterior, lo que le permitiría llevar a cabo operaciones de alta intensidad en la lucha contra el terrorismo y las amenazas híbridas ${ }^{23}$. En definitiva, la UE se convertiría en un proveedor de seguridad más fuerte y reactivo, con autonomía estratégica para actuar en solitario o junto con sus socios principales, estando más directamente comprometida con la protección de sus Estados miembros y de sus ciudadanos.

c) Defensa y seguridad comunes: es el escenario más ambicioso y supone la creación de la Unión de Seguridad y Defensa de acuerdo

22 Ibidem, p. 13.

23 Ibidem, p. 13. 
con las posibilidades que encierra el artículo 42 del Tratado que prevé el desarrollo gradual de una política de común de defensa de la Unión que conduciría a una defensa común. En este escenario, los Estados miembros profundizarían más en la cooperación y la integración en pos de una defensa y una seguridad comunes. La UE contará con capacidad para llevar a cabo operaciones ambiciosas, con autonomía estratégica y con la protección de Europa como responsabilidad propia. La planificación en materia de defensa de los Estados miembros se sincronizaría completamente y las prioridades nacionales para el desarrollo de capacidades tendrían en cuenta las prioridades europeas. Tales capacidades se desarrollarían sobre la base de una estrecha cooperación, o incluso de una integración o especialización ${ }^{24}$.

Resumiendo: el escenario primero implica «cooperación» en materia de seguridad y defensa; el segundo supone una seguridad y defensa «compartida»; en el tercero se trata de disponer de una seguridad y defensa «común». El documento de la Comisión abre perspectivas; no es fácil aventurar donde estaremos en 2025 en materia de seguridad y defensa; pero lo que sí podemos asegurar es que el escenario primero está ya superado. Como veremos en las siguientes páginas, en los últimos meses se han adoptado medidas que nos colocan en el segundo escenario (Fondo Europeo de Defensa, coordinación intensa entre OTAN/UE, solidaridad operativa y financiera entre los Estados miembros en el marco de la Cooperación Estructurada Permanente que veremos posteriormente, acercamiento estratégico como consecuencia de la implementación de la Estrategia Global, etc. ${ }^{25}$. Que pasemos al escenario tres dependerá de la voluntad política de los Estados y de su comprensión acerca de la dimensión del desafío ${ }^{26}$.

24 Ibidem, p. 15.

25 En sentido parecido, aunque un poco más cauta es la valoración de ACOSTA SÁNCHEZ cuando afirma que «(...) la labor y los objetivos marcados en el seno de la PCSD actualmente, con la Cooperación Estructurada Permanente como figura más destacada, nos hace presagiar una clara voluntad de alcanzar el escenario b), y con visos de aproximarse al escenario c)». Vid. «La Cooperación Estructurada Permanente: ¿un primer paso hacia la integración en la seguridad y defensa europeas?»; en Revista General de Derecho Europeo, 45, 2018 (pp. 10 y 11).

${ }^{26}$ Como afirma Nicolas Clinchamps tras analizar cada uno de los tres escenarios señalados «(...) le succès de la défense de 1’Europe será le salut de 1'UE. Son échec pourrait être son tombeau»; en «Trois scénarios pour l'avenir de l’Europe de la défense»; Revue de Droit de l'Union Européenne, 3, 2017, p. 175. 


\section{Nuevos desarrollos de la PCSD: hacia una Unión de la Seguridad y la Defensa}

Desde el 28 de junio de 2016 cuando se presentó la Estrategia Global para la política Exterior y de Seguridad ${ }^{27}$ hasta nuestros días, nunca la Defensa había ocupado un lugar tan relevante en la agenda comunitaria. Las realizaciones de los últimos dos años nos llevan a pensar que nos encontramos en el umbral de una verdadera Unión Europea de la Seguridad y la Defensa. Indudablemente, el Brexit ha sido la ventana de oportunidad para ello al tener el efecto de «soltar lastre» y permitir el avance en una materia crítica permanentemente cortocircuitada por la oposición del socio británico. Las incertidumbres provocadas por el acceso de Donald Trump a la presidencia estadounidense acabaron de despejar las dudas acerca de la necesidad de evolucionar en este ámbito permanentemente pospuesto (al abrigo que proporcionaba, precisamente, la alianza atlántica ahora en entredicho). El surgimiento de nuevas amenazas, así como el deterioro de las condiciones de seguridad en la vecindad de la UE (conflicto de Ucrania, política agresiva de Putin, primaveras árabes y consecuencias en Libia, Yemen, Siria, Turquía, etc.) hizo el resto. En apenas algo más de dos años, concretamente desde la presentación de la Estrategia Global/referéndum del Brexit, hemos dado pasos impensables hasta hace muy poco tiempo en materia de seguridad y defensa. Para algunos, estaríamos asistiendo al nacimiento de la Europa de la Defensa, más de seis décadas después del fracaso de su primer intento en 1950 con la Declaración Pleven sobre el establecimiento de una Comunidad Europea de Defensa. En el tiempo transcurrido desde el 28 de junio de 2016 (presentación de la Estrategia Global) hasta hoy, la Unión de la Defensa ha avanzado más que desde el lanzamiento de la primera misión operativa de la PESD en 2003 hasta 2016. Estas son las principales realizaciones.

\section{La Estrategia Global para la Política Exterior y de Seguridad de la UE}

Presentada el 28 de junio de 2016 (cinco días después del referéndum del Brexit y cinco meses antes de la victoria de Donald Trump) tiene por objeto orientar la política exterior y de seguridad de la UE en los próximos años. Enumera las cinco prioridades de la acción exterior de la UE: seguridad, fomento de la resiliencia en nuestros vecinos tanto del este como del

27 Doc. Consejo 10715/16, Estrategia Global sobre Política Exterior y de Seguridad de la Unión Europea: una visión común, una actuación conjunta: una Europa más fuerte, de 28.06.2016. 
sur, enfoque integrado de los conflictos, promoción de órdenes regionales de cooperación en todo el mundo, fomento de una gobernanza mundial para el siglo XXI. La Estrategia afirma que «debemos asumir una mayor responsabilidad en nuestra seguridad. Frente a las amenazas externas, debemos estar preparados y capacitados para ejercer disuasión, dar respuesta y protegernos (...) así como para actuar de manera autónoma en el caso y en el momento necesario. Un nivel adecuado de ambición y autonomía estratégica es importante para la capacidad de Europa de fomentar la paz y garantizar la seguridad dentro y fuera de sus fronteras» (p. 14).Aunque refuerza la idea del «soft power» («La UE siempre ha estado, y seguirá estando, orgullosa de su poder no coactivo, porque en ese terreno somos los mejores», p.3), propone reforzar la cooperación en materia de defensa («Para Europa, el poder no coactivo y el poder coactivo van de la mano») hasta alcanzar la autonomía estratégica.

La Estrategia ha sido considerada por la doctrina como un texto posibilista, realista y adaptado a las circunstancias del momento ${ }^{28}$; en nuestra opinión, una de las principales aportaciones que realiza es la apuesta por la promoción de la defensa explícita de los intereses comunes y no solo de los valores como ocurría hasta ahora. La política de defensa de la UE deja de estar limitada a la realización de operaciones de gestión de crisis en el exterior para convertirse en un instrumento para la defensa de ciudadanos y territorios, lo que significa la defensa territorial, hasta el momento competencia de los Estados miembros (y de la OTAN), algo que para algunos supone la aportación más importante de la Estrategia y un cambio cualitativo del alcance de la política de defensa ${ }^{29}$. La evidencia de que no estábamos ante un texto meramente declarativo (o de que la coyuntura que lo acompañó iba a convertirlo en un instrumento de vocación práctica) fueron las realizaciones en cascada que lo siguieron y que nos ocuparán seguidamente.

28 Vid. entre otros: BARBÉ, E.; «La Estrategia Global de la Unión Europea: el camino del medio»; Revista General de Derecho Europeo, 40, 2016, p. 5; LIÑAN NOGUERAS, D.; «Un nuevo discurso estratégico para la política exterior de la Unión Europea», Revista de Derecho Comunitario Europeo, 56, 2017. SANAHUJA, J.A.; VERDES-NONTENEGRO, F.J.; «Estrategias de seguridad y desarrollo: discursos securitarios en la Unión Europea, Estados Unidos y España»; MESA, M. (Coord.); Derechos humanos y seguridad internacional: amenazas e involución. Anuario 2017-2018, Madrid, CEIPAZ, 2018.WAGNER, W. ANHOLT, R.; «Resilience as the EU Global Strategy's new leitmotif: pragmatic, problematic or promising?», Contemporary Security Policy, 2016 (DOI: 10.1081/13523260.2016.1228034)

${ }^{29}$ ALDECOA LUZARRAGA, F.; «La política de defensa de la Unión Europea en el marco de la aplicación de la Estrategia Global para la Política Exterior y de Seguridad»; LÓPEZ GARRIDO, D. (Dir.); El estado de la Unión Europea. Relanzar Europa. Madrid, Fundación Alternativas, 2017, p. 77. 


\section{El Plan de Acción Europeo de la Defensa}

Concebido como un plan de trabajo para desarrollar y materializar la Estrategia Global ${ }^{30}$. Se basa en tres pilares: la creación de un Fondo Europeo de Defensa (que veremos en el siguiente epígrafe); la facilitación de las inversiones en el sector; y la consecución de un mercado único de la defensa $^{31}$. En definitiva, pretende hacer más eficiente el gasto en capacidades de defensa conjuntas y fomentar una base industrial competitiva e innovadora en tecnologías y equipos estratégicos; es la primera vez que se lanza un plan específico para apoyar la industria de defensa e incluye la creación de un verdadero mercado único de la defensa abierto y competitivo acabando con la fragmentación actual de los mercados europeos de defensa.

\section{Fondo Europeo de Defensa -FED-}

Se pone en marcha el 2017 para apoyar la inversión en investigación conjunta y el desarrollo conjunto de equipos y tecnologías de defensa ${ }^{32}$. Posteriormente, el FED ha quedado integrado en el próximo Marco Financiero Plurianual 2021-2027, con una propuesta de dotación de $13.000 \mathrm{mi}-$ llones de euros .Como es sobradamente conocido, el gasto militar europeo es el segundo más grande del mundo tras el de EEUU; sin embargo, es también un gasto con altas dosis de ineficiencia debido a duplicaciones, falta de interoperabilidad, brechas tecnológicas y carencia de economías de escala para la producción industrial (cerca del $80 \%$ de la contratación pública en defensa se realiza sobre una base puramente nacional, lo que origina esas disfunciones) $)^{33}$. El FED incluye dos secciones complementarias: a) sección de investigación para el financiamiento de investigación colaborativa en tecnologías de defensa; b) sección de desarrollo y adquisición de equipos de defensa que permitirá a aquellos Estados que lo deseen adquirir conjuntamente tales equipos en cofinanciación con el presupuesto comunitario. Tras la conclusión del Programa Europeo de Desarrollo Industrial en materia de Defensa, comenzaran a financiarse proyectos concretos en el 2019.

30 Plan de Acción Europeo de la Defensa, Bruselas, 30.11.2016, COM (2016) 950 final.

31 ROLDÁN BARBERO, J.; «La Europa de la defensa pasa a la ofensiva»; en Revista General de Derecho Europeo, n. ${ }^{\circ} 43,2017$, p. 4.

32 Launching the European Defence Found, Bruselas, 7.06.2017, COM (2017) 295 final. A principios del 2018 se estableció una dotación incial de 500 millones de euros para llevar a cabo un primer Programa Europeo de Desarrollo Industrial en material de Defensa a desarrollar durante 2019-2020.

33 Vid. el Informe del Parlamento Europeo The Cost of Non-Europe in Common Security and Defence Policy, Bruselas, 2013. 


\section{Relaciones UE-OTAN}

La Declaración conjunta sobre la cooperación UE/OTAN en la Cumbre de Varsovia del 8 de julio de 2016 definirá un marco común de relación basado en la Estrategia Global en materia de cooperación operativa, ciberseguridad y ciberdefensa, capacidades y maniobras coordinadas, etc. Obviamente, la relación OTAN/UE debe basarse en la complementariedad, evitando duplicidades; pero esto no puede negar la necesidad de la UE de contar con una capacidad autónoma de defensa potencialmente utilizable en zonas de interés no concordantes con las de la Alianza Atlántica. Buena parte de las necesidades de defensa actuales en Europa, no encajan siempre en la operativa de la OTAN. Así, mientras que los Países Bálticos quedarían protegidos por la OTAN ante una eventual agresión rusa, Finlandia -Estado neutral - no lo estaría. Lo mismo puede decirse para eventuales conflictos en el Sahel, el Sur de Mediterráneo, etc.; así como otros problemas como el yihadismo, la migración descontrolada o los ciberataques, situaciones que, sin ser conflictos bélicos propiamente, podrían requerir también de una actuación militar.

La llegada de Trump a la presidencia, unos meses más tarde de la referida Declaración conjunta UE-OTAN, ha contribuido a enrarecer la relación entre los socios atlánticos como consecuencia de las reiteradas y poco diplomáticas llamadas del Presidente estadounidense al necesario aumento de financiación europea a la Organización. El debate es complejo y desde luego, excede del objetivo de este artículo, pero las cosas no son tan simples como señala Trump en sus tweets. La contribución directa de EEUU al presupuesto civil y militar de la Alianza es un $22 \%$ del presupuesto total de la Organización; mientras que los europeos asumen conjuntamente $2 / 3 \mathrm{del}$ presupuesto (y el monto restante es asumido por los aliados no europeos); solo la contribución franco-alemana es ya superior a la estadounidense: $25 \%$ del presupuesto de la Alianza ${ }^{34}$. Además, no podemos olvidar el papel motor del presupuesto militar estadounidense en tanto que factor de crecimiento económico por sus pedidos a la industria nacional propia, dado que EEUU apenas compra en el extranjero, contrariamente a lo que todavía hoy hacen los europeos. Es decir, los casi 500 millones de euros/año con los que EEUU contribuye a la OTAN son una inversión, ya que son ampliamente rentabilizados por las compras europeas en el mercado armamentístico estadounidense. Por último, recordemos lo obvio: los Estados miembros solo poseen un conjunto único de fuerzas susceptibles de utilizar en diferentes

${ }^{34}$ GROS-VERHEYDE, N; «Trump tâcle le projet Macron d’armée européenne. A-t-il raison?. Bruxelles2Pro,noviembre 2018 (http: //www.bruxellees2.eu). 
marcos; así, el desarrollo de las capacidades de los Estados miembros en el marco de la PCSD, también ayudará por tanto a reforzar las capacidades potencialmente disponibles para la OTAN.

\section{Capacidad Militar de Planificación y Ejecución}

Creada el 8 de junio de 2017 que permitirá en lo sucesivo asumir el mando de las misiones militares no ejecutivas de la $U^{35}$ y se convertirá en el futuro, probablemente, en un verdadero Cuartel General Permanente que posibilite la planificación, mando y ejecución de todo el espectro de misiones operativas de la UE y la «reacción rápida» sin tener que recurrir, como ocurre ahora, a los recursos de los Estados miembros al efecto (Cuarteles Militares nacionales puestos a disposición de la Política Común de Seguridad y Defensa ubicados en Reino Unido, Alemania, Francia, Italia o Grecia; o a las estructuras de planeamiento de la OTAN $)^{36}$. Es la primera estructura propiamente militar de que se dota la UE y su adaptación solo ha sido posible por el Brexit, dado que el Reino Unido venía bloqueando desde hacía tiempo ese «cuartel militar operativo» europeo.

\section{La Cooperación Estructurada Permanente - PESCO, según las siglas en inglés-}

Es la última de las realizaciones en materia de seguridad y defensa llevadas a cabo. Adoptada en diciembre de $2017^{37}$, se trata de una cooperación militar reforzada y permanente, especie de «núcleo duro» o Schengen de la defensa según algunos, contemplada en el artículo 42.6 Tratado de Lisboa y que posibilita la profundización progresiva y gradual en la cooperación

35 Son aquellas misiones de naturaleza militar, pero dedicadas a la formación del ejército local. Actualmente hay tres misiones de esta naturaleza en Mali, Somalia y la República Centroafricana.

36 El Consejo de Seguridad y Defensa del 19 de noviembre de 2018 se fija el objetivo de «estar en disposición, a más tardar a fin de 2020, de asumir la responsabilidad de la planificación y ejecución operativas de las misiones PCSD militares no ejecutivas y una misión PCSD militar ejecutiva limitada a la dimensión de un grupo de combate de la UE». Vid. Conclusiones del Consejo (19 de noviembre de 2018), 13978/18, punto 5. Aunque no parece un avance muy grande, no podemos olvidar que es un paso cualitativo y que todos los grandes proyectos se inician con una iniciativa modesta que adquiere una dinámica propia de crecimiento.

37 Decisión 2017/2315/PESC del Consejo, de 11 de diciembre de 2017, por la que se establece una cooperación estructurada permanente y se fija la lista de Estados miembros participantes. DO, L 331, de 14.12.2017. 
en materia de defensa entre los Estados miembros que tengan capacidad y voluntad en ello. Será el Consejo de la PESCO el encargado de establecer si se cumplen o no los compromisos mínimos y obligatorios establecidos para formar parte de la cooperación referida. Ésta, tiene como objetivo reforzar conjuntamente las capacidades comunitarias de defensa y ponerlas a disposición de la UE para la materialización de operaciones militares comunitarias y permitirle así avanzar hacia la «autonomía estratégica». Puede considerarse como el paso más importante dado hasta el momento para la constitución de una Europa de la Defensa que se irá dotando de más contenido en el futuro. En la PESCO participan finalmente 25 Estados miembros (es decir, todos salvo Reino Unido, Dinamarca y Malta), aunque de forma distinta, permitiendo diferentes niveles de participación, sin que todos los integrantes deban incluirse obligatoriamente en todos los proyectos definidos hasta el momento ${ }^{38}$. En definitiva, PESCO es un proyecto político que echa a andar con un claro compromiso por parte de prácticamente todos los Estados miembros de poner en marcha un dispositivo que debe ir creciendo en el futuro próximo ${ }^{39}$. La PESCO no es un mero compromiso político más, como otros que se han producido en el pasado en este ámbito y que adolecieron de falta de consecuencias prácticas; sino que ahora estamos ante un acuerdo vinculante para avanzar a una mayor velocidad en materia de defensa. La PESCO «es el primer compromiso jurídico exigible a 25 Estados miembros para actualizar, modernizar y adecuar sus capacidades militares, estructuras y equipos de defensa» ${ }^{40}$.

Todo este instrumental que nos ha ocupado en las páginas anteriores acerca del andamiaje que estamos construyendo en materia de seguridad y

${ }^{38}$ El 6 de marzo de 2018 se adoptaron formalmente los 17 primeros proyectos que se habían acordado el 11 de diciembre de 2017. Estos abarcan ámbitos como la formación, el desarrollo de capacidades, etc. Cada uno de ellos será gestionado por los Estados miembros que contribuyan a él y se comprometan en él. Cada país participa en al menos un proyecto, aunque en general participan en varios. Cada proyecto debe integrar por lo menos a dos países, aunque la media es de una participación de entre tres y seis por proyecto. En esta primera tanta, Italia es el país que más proyectos lidera, (4 de 17) y participa en otros 12. El Consejo de Seguridad y Defensa del 19 de noviembre de 2018 aprobó 17 nuevos proyectos (entre otros: el proyecto sobre el futuro eurodron MALE que deberá estar operativo para el año 2025, la nueva versión del helicóptero Tigre, una red de bases para dar apoyo logístico a las operaciones europeas, un plan de mejora de los sistemas de radionavegación a través del sistema europeo Galileo, etc.). Inicialmente España participará en 6 de estos 17 nuevos proyectos.

39 GROS-VERHEYDE, N., «Give PESCO a chance» en Bruselles Pro, Décembre, 2017 (www.bruxelles2.eu/2017/12/give-pesco-a-chance/)

${ }^{40}$ LÓPEZ-JACOISTE, E.; «La nueva Cooperación Estructurada Permanente: ¿impulso definitivo para una verdadera PCSD en Europa?»; Anuario Español de Derecho Internacional, n. 34 , 2018, p. 1095 (DOI 10.15581/010.34.1075-1097) 
defensa no debe confundirnos; como señaló Juncker en su último Discurso sobre el Estado de la Unión es necesario hacer una precisión importante: «no militarizaremos la UE. Lo que queremos es hacernos más responsables y más independientes ${ }^{41}$. Un actor global como la UE debe responsabilizarse de su propia seguridad y defensa; en la coyuntura actual, y con el deterioro de la seguridad en nuestra vecindad, esto ya no es una opción, sino una obligación y una necesidad. No se trata de transformar la naturaleza de la UE, convirtiéndola en un actor militar; sino de que pueda defender su modelo de sociedad, sus valores e intereses sin sentirse vulnerable ni condicionada por presiones de naturaleza militar de otros actores internacionales ${ }^{42}$.Pero, en sentido contrario, tampoco podemos obviar que la coyuntura de la policrisis comunitaria, y más concretamente las consecuencias derivadas del Brexit por una parte y del acceso de Trump al poder, han colocado a la PCSD en una posición central en la agenda comunitaria. Se trata, precisamente, de una de las pocas políticas que permanecía en el núcleo duro de la soberanía estatal y que requería de una potenciación clara y efectiva. Ahora, la Unión de la Seguridad y la Defensa es ya un objetivo tangible y susceptible de ser alcanzado en plenitud ${ }^{43}$.

\section{El Reino Unido y la defensa comunitaria tras el Brexit: la iniciativa europea de intervención}

Son muchos los análisis sobre el Brexit que han puesto el acento en los efectos que tendría sobre la configuración de la UE como un actor potente en materia de seguridad y defensa; pues no en vano, el Reino Unido es el primer país comunitario en la materia, con las más importantes y mejor dotadas fuerzas con capacidad nuclear, convencional y expedicionaria en el seno de la Unión, con uno de los más importantes presupuestos en materia

41 JUNCKER, J.-C.; Estado de la Unión 2018. La hora de la soberanía europea, 12 de septiembre de 2018. P. 5 .

${ }^{42}$ En palabras del Presidente Juncker, «(...) Europa es una potencia suave. Pero ni las más sólidas de esas potencias pueden funcionar a largo plazo sin algunas capacidades de defensa integradas». Orientaciones Políticas de la Comisión Europea del 15 de julio de 2014. En sentido semejante, ALDECOA, F. se interroga sobre la necesidad de la política de defensa, para responderse que tal política es imprescindible para que la UE pueda funcionar como el actor global que ya es, sin que su actividad sea condicionada por presiones de carácter militar por parte de otros actores; en «El referéndum británico: un grave problema para el Reino Unido y para la Unión Europea y una oportunidad para el proyecto europeo»; Cursos de Derecho Internacional y Relaciones Internacionales de Vitoria-Gasteiz, 2016. Pamplona, Aranzadi, 2017, p. 130.

43 Valoración que extraemos de ACOSTA SÁNCHEZ, M.A., op. cit.p. 47. 
de defensa y una de las más potentes industrias militares del mundo. Además de contar con su representación permanente en el Consejo de Seguridad. Así, se concluía que, sin los británicos, la posibilidad de construir una Unión de la Seguridad y la Defensa se quedaba en una mera entelequia. No solo perderíamos capacidad militar, sino también capacidad policial y de inteligencia ante riesgos no propiamente militares, como el terrorismo, la ciberdelincuencia, etc. La historia parecía apoyar esta idea pues no podemos olvidar que la entonces denominada Política Europea de Seguridad y Defensa nació como consecuencia de la iniciativa de británicos y franceses en la Cumbre de Saint Malo de $1998^{44}$.

La participación británica fue decisiva para el desarrollo inicial de la seguridad y defensa comunitaria; sin embargo, este compromiso se fue debilitando progresivamente hasta dejar de ser un actor esencial en la PCSD de nuestros días dado que, para ellos, la seguridad y defensa comunitaria no ocupa sino un papel secundario respecto del que ocupa la Alianza Atlántica. En la actualidad el Reino Unido es solo el quinto de los contribuyentes a las misiones militares, tras Francia, Italia, Alemania y España; y el séptimo en las operaciones civiles ${ }^{45}$. La aportación británica en número de efectivos da cuenta del carácter meramente testimonial que para ellos tiene la PCSD; así, del total de más de 3500 militares desplegados en las diferentes misiones comunitarias en 2016, Reino Unido solo aportaba aproximadamente $180^{46}$. Además, no solo ocurre que su participación sea escasa, sino que además se produce en lugares de interés para Reino Unido; y en el resto de teatros su presencia no es ni siquiera testimonial, es inexistente.

La paradoja, según anticipamos en las páginas anteriores, es que la progresión hacia una Unión de la Seguridad y de la Defensa, y singularmente la puesta en marcha de la PESCO, se puede producir en los últimos meses, precisamente como consecuencia de que el Reino Unido pierde la capacidad que tenía hasta ahora de vetar sistemáticamente su desarrollo. Más paradójico resulta todavía el hecho de que la misiva que envía Theresa May al Consejo Europeo el 29 de marzo de 2017 para comunicar la decisión britá-

${ }^{44}$ Sobre este acontecimiento vid. DE CASTRO RUANO, J.L.; «La Política Europea de Seguridad y Defensa (PESD) y la evolución de las relaciones transatlánticas en el contexto de la crisis de Irak»; Cursos de Derecho Internacional y Relaciones Internacionales de VitoriaGasteiz, 2004. Leioa, Servicio Editorial de la UPV/EHU, 2005, pp. 93 y ss.

45 Datos que tomamos de ALDECOA LUZARRAGA, F.; «La Cooperación Estructurada Permanente: haciendo creíble la Alianza Defensiva de la Unión Europea, sin perder la condición de potencia normativa y diplomática»; en Anuario Español de Derecho Internacional, n. ${ }^{\circ}$ 34, 2018, p. 1018.

46 Vid. MONTOYA CERIO, F.; «Brexit, ficción o realidad: impacto sobre la PCSD de la UE» en Documento Opinión del Instituto Español de Estudios Estratégicos, n. ${ }^{\circ} 64$ bis, 2016 de 24 de junio de 2016 (www.iee.es), p. 12 y 13. 
nica de abandonar la Unión, incluye un deseo implícito de mantener la relación en materia de seguridad y defensa. Posteriormente, el Gobierno británico afirmará su voluntad de participar en todos los desarrollos en materia de seguridad y defensa, aún en el caso de que estos se produzcan fuera del marco comunitario ${ }^{47}$; luego, en la Conferencia de Munich sobre Seguridad celebrada el 17 de febrero de 2018, la Primera Ministra británica apuesta por la firma de un Tratado de Defensa y de Seguridad con la UE que podría entrar en vigor, afirmó, antes incluso de que se materializase su salida del club comunitario. Este futuro tratado cubriría la cooperación en el ámbito militar, la investigación y la lucha contra el terrorismo; ello implica disposiciones sobre las misiones militares comunes de la UE, la participación de tropas británicas en estas misiones y capacidades de defensa. En Munich May apeló a una asociación profunda y especial sobre la defensa asegurando que «el Reino Unido está más comprometido que nunca con la seguridad europea ${ }^{48}$. Es decir, el Reino Unido lanza mensajes acerca de su voluntad de participar en la PCSD desde fuera, de manera análoga a como lo vienen haciendo algunos otros países no comunitarios, como Noruega. Así, no deberíamos descartar la posibilidad de que, en un futuro no muy lejano, el Reino Unido se incorporara a la Cooperación Estructurada Permanente cuyo desarrollo y puesta en marcha tantas veces bloqueó como país miembro, así como a otras iniciativas comunitarias en la materia.

De hecho, el Ministerio británico de defensa viene participando en el Examen Anual Coordinado en Materia de Defensa - CARD según sus siglas en inglés - ; iniciativa lanzada en 2017 en el marco de las medidas tomadas para dinamizar la seguridad y la defensa comunitaria que tiene como objetivo la coordinación de los presupuestos europeos de defensa. Recordemos también que la Agencia Europea de Defensa tiene acuerdos con diferentes países terceros (Noruega, Ucrania, etc.) que les permite participar en determinados proyectos; es decir, nada impediría al Reino Unido desarrollar una participación semejante siendo un país tercero; lo mismo podríamos señalar del Fondo Europeo de Defensa, por ejemplo.

También, en pleno proceso de negociación del Brexit, el Reino Unido se incorpora a una de las iniciativas de defensa más potentes creadas recientemente en Europa y por países de la UE, si bien, fuera del marco comunitario. Me refiero a la denominada Iniciativa Europea de Intervención -en adelante IEI - nacida el 25 de junio de 2018 por iniciativa del Presidente

47 Vid. ALDECOA LUZARRAGA, F.; «Un nuevo compromiso relevante y exigente de los Estados miembros en materia de seguridad y defensa: la Cooperación Estructurada Permanente (PESCO)», en LÓPEZ GARRIDO, D. (Dtor.); El estado de la Unión Europea. Los Estados europeos ante la reforma de la Unión. Madrid, Fundación Alternativas, 2018, p. 117.

48 Vid. «May prépare un traité sur la défense avec 1’UE» en www .euractiv.fr, 20/02/2018. 
francés Emmanuel Macron y que integra además de a Francia y al Reino Unido, a España, Alemania, Holanda, Bélgica, Dinamarca, Estonia, Portugal y Finlandia ${ }^{49}$. Salvo Italia, que finalmente decidió permanecer al margen, la IEI incorpora a todos los Estados con importante capacidad de defensa además de otros países medianos; Estonia sería una excepción, si bien la República báltica aporta una gran experiencia en amenazas híbridas, singularmente en ciberataques, cuestión clave en cualquier estrategia de seguridad de nuestros días. De forma voluntaria, la IEI limita el número de países integrantes, para constituir un «núcleo duro» susceptible de desarrollar misiones potentes en caso de necesidad.

En junio de 2018, los países referidos — salvo Finlandia que se adhirió posteriormente - firmaron una «Carta de intenciones» para sellar su compromiso de crear una fuerza común de intervención militar que agilice los procedimientos de actuación en misiones militares - y también de tipo civil- de interés común. Se trata de que aquellos países militarmente capaces y con voluntad política para ello, establezcan habilidades para trabajar conjuntamente en el campo estratégico y se preparen para intervenir, si fuera necesario, en escenarios de seguridad y defensa muy variados. Con esta iniciativa Francia logra dos objetivos: en primer lugar, ir más lejos de la PESCO y avanzar en su objetivo de establecer un núcleo duro de la defensa«no inclusivo», más ambicioso y operacional, potencialmente capaz de desarrollar misiones exteriores de envergadura (algo para lo que inicialmente los Tratados contemplaban la PESCO pero que, por el perfil más inclusivo y centrado en la consecución de capacidades comunes y no en la realización de misiones que adoptó finalmente por presión de Alemania, no logrará ${ }^{50}$ ); en segundo lugar, mantener al Reino Unido como aliado militar una vez se consume su abandono de la Unión Europea. La IEI es una iniciativa que permite asociar a Estados extracomunitarios, por lo que los británicos podrían así continuar su participación en los programas de defensa de la UE.

Según la «Carta de intenciones» del 25 de junio, la Iniciativa se concentrará sobre cuatro ámbitos ${ }^{51}$ : previsiones estratégicas e inteligencia compartida; desarrollo de escenarios y planificación; apoyo a las operaciones; comentarios de experiencias.Entre los diferentes escenarios de intervención previstos figuran: la evacuación de ciudadanos europeos, acción humanitaria en caso de crisis con el apoyo de fuerzas armadas, intervenciones dirigi-

49 El país nórdico se integró más tarde, en noviembre de 2018.

${ }^{50} \mathrm{Si}$ bien Angela Merkel apostó porque la IEI sea incluida en su momento en la PESCO, como uno más de sus proyectos. Vid. «L'initiative européenne d'intervention», n. ${ }^{\circ} 62,18$ juin 2018 (https: //club.bruxelles2.eu)

51 Vid.»Huit pays adhérent á 1'initiative européenne d’intervention d’E. Macron. La lettre d’intention signée», 25 juin 2018(https: //club.bruxelles2eu) 
das (biológicas, médicas, etc.); si bien, las intervenciones de fuerza parecen ser los escenarios más contemplados. El objetivo principal es lograr una interpretación compartida desde el punto de vista estratégico que permita incluso el intercambio de fuerzas armadas para desarrollar intervenciones militares clásicas. La iniciativa no pretende duplicar la PESCO; antes bien, pretende complementar las diferentes iniciativas comunitarias en la materia que nos ocuparon en las páginas anteriores, con una iniciativa en el campo estratégico de la que carecían las anteriores (sea la PESCO, el Fondo Europeo de Defensa, el Plan de Acción Europeo de la Defensa, etc.).

\section{Conclusiones}

Así las cosas, parece evidente que, en el futuro, la UE y el Reino Unido deberán quedar vinculados de forma flexible por algún tipo de acuerdo en materia de seguridad y defensa ${ }^{52}$. De momento, vemos que el Reino Unido pretende mantenerse anclado a la principal iniciativa multilateral estratégica de defensa de naturaleza puramente europea. Sin olvidar además que este país ha desarrollado también un entramado de relaciones bilaterales y multilaterales en materia de seguridad y defensa dentro de la UE que pueden mantenerse ya que no necesariamente tienen que verse afectadas por el abandono de la Unión. De entre todas ellas, quizá la más relevante por los socios que la protagonizan y su nivel de ambición son los Acuerdos de Lancaster House, firmados por Reino Unido y Francia en 2010. Además, existen otros compromisos menos ambiciosos con algunos países nórdicos para la creación de unidades bilaterales conjuntas, etc.

En cualquier caso, parece obvio que aunque el Reino Unido mantenga una relación con la PCSD, lo que ya nunca podrá hacer es condicionar las orientaciones políticas y estratégicas que adopte la UE, sea en el Sahel, en la relación con Rusia, en Siria, en Irán o en tantos otros escenarios de confrontación ${ }^{53}$. Con el Brexit, la UE perderá a uno de los socios con una cultura estratégica más decidida y menos dubitativa en cuanto a la utilización de la fuerza como instrumento de política exterior, frente a una mayoría de países comunitarios que hoy siguen priorizando la dimensión securitaria de la PCSD y el «poder blando». En unos momentos en los que la UE deberá plantearse decisiones más audaces en lo que se refiere a la decisión de utilizar y desplegar el poder militar, esto puede restar capacidades que ha-

52 DASSÚ, M.; ISCHINGER, W., et al; Keeping Europe Safe After Brexit. 20, march, 2018, European Council of Foreign Relations (www.ecfr.eu).

53 ARTEAGA, F., «La defensa y la seguridad de la UE tras el Brexit»; en Análisis del Real Instituto ARI, 51/2016 (www.realinstitutoelcano.org). 
brán de completar el sobreesfuerzo del resto de socios comunitarios, Francia especialmente, pero probablemente también otros. Sin embargo, la otra cara de la moneda es que el Reino Unido dejará de cortocircuitar la voluntad comunitaria de avanzar en este ámbito de manera que, como estamos ya viendo, la puesta en marcha de diferentes iniciativas en materia de seguridad y defensa puede llevarnos en no demasiado tiempo a dar el salto hacia la integración; si bien, probablemente será una forma de integración diferenciada en la que la flexibilidad será la característica dominante en otro ámbito en el que tampoco todos avanzaremos al mismo ritmo. Con todas las cautelas con las que debe moverse cualquier prospectiva en materia de seguridad y sobre todo de defensa común, no podemos negar que estamos transitando, hemos transitado ya, hacia un escenario cualitativamente diferente donde incluso, hablar de un ejército europeo ha dejado de ser un tabú ${ }^{54}$. Aunque no quede claro qué es exactamente lo que los líderes quieren significar cuando se refieren a ello, sí parece evidente que no evocan simplemente un proyecto de cooperación sino algo más cercano a un verdadero ejército europeo a constituir en un todavía impreciso largo plazo fuera de los tratados o con otro tratado distinto al actual ${ }^{55}$. Con todo, no parece descabellado afirmar que en materia de seguridad y defensa estamos dando el paso hacia la integración que implica la Unión de la Seguridad y la Defensa a la que se refería la Comisión en el tercer escenario de su Documento de Reflexión sobre el Futuro de la Defensa analizado en este trabajo.

\section{Bibliografía}

AA.VV. More Union in European Defense. Report of a CEPS Task Force. Brussels: Centre for European Policy Studies, 2015.

Acosta Sánchez, Miguel Á. «La Cooperación Estructurada Permanente: ¿un primer paso hacia la integración en la seguridad y defensa europeas?». Revista General de Derecho Europeo, n. ${ }^{\circ} 45$ (2018): 58-106.

Aldecoa Luzarraga, Francisco. «La relevancia de la Agenda del relanzamiento europeo en el 60. aniversario del Tratado de Roma y en $70 .^{\circ}$ del Congreso de Europa en La Haya». En Europa como tarea. A los sesenta años de los Tratados de Roma y a los setenta del Congreso de Europa de la Haya, Eugenio Nasarre, Francisco Aldecoa y Miguel Á. Benedicto (Coords), Madrid: Marcial Pons, 2018.

54 «Armée européenne: un tabou est levé», 16/11/2018 (www.euractiv.fr)

55 Recordemos que el TUE excluye la formación de un ejército comunitario ya que en su artículo 42.3 afirma que «los Estados miembros pondrán a disposición de la Unión, a efectos de la aplicación de la PCSD, capacidades civiles y militares»; esto es, lo que contempla es que las capacidades militares sigan siendo de los Estados y las pongan a disposición de la Unión. Vid. también el final del art. 42.1. 
Aldecoa Luzarraga, Francisco. «La Cooperación Estructurada Permanente: haciendo creíble la Alianza Defensiva de la Unión Europea, sin perder la condición de potencia normativa y diplomática». Anuario Español de Derecho Internacional, n. 34 (2018): 1003-1020.

Aldecoa Luzarraga, Francisco. «La política de defensa de la Unión Europea en el marco de la aplicación de la Estrategia Global para la Política Exterior y de Seguridad». En El estado de la Unión Europea. Relanzar Europa, Diego López Garrido (Dir.). Madrid: Fundación Alternativas, 2017.

Aldecoa Luzarraga, Francisco. «El referéndum británico: un grave problema para el Reino Unido y para la Unión Europea y una oportunidad para el proyecto europeo». En Cursos de Derecho Internacional y Relaciones Internacionales de Vitoria-Gasteiz, 2016, 103-182. Pamplona: Aranzadi, (2017).

Álvarez Verdugo, Milagros; «Actores, procedimientos y capacidades de la Política Común de Seguridad y Defensa». En La Unión Europea en las relaciones internacionales, Esther Barbé (Dir.). Madrid: Tecnos, 2014.

Arteaga, Félix. «La defensa y la seguridad de la UE tras el Brexit». Análisis del Real Instituto ARI, 51/2016 (www.realinstitutoelcano.org).

Barbé, Esther. «La Estrategia Global de la Unión Europea: el camino del medio». Revista General de Derecho Europeo, n. ${ }^{\circ} 40$ (2016): 1-10.

Barbé, Esther. «Las primeras víctimas de la crisis iraquí: el prestigio de Europa como actor internacional y la capacidad negociadora de España en el marco de la UE». Revista General de Derecho Europeo, n. ${ }^{\circ} 1$ (2003). (www.iustel.com).

Clinchamps, Nicolas. «Trois scénarios pour l'avenir de 1'Europe de la défense». Revue de Droit de l'Union Européenne, n. 3 (2017): 163-175.

Comisión Europea. COM (2017) 315 Documento de reflexión sobre el futuro de la defensa europea. Comisión Europea (7 de junio de 2017).

Comisión Europea. COM (2017) 295 final, Launching the European Defence Found, Bruselas, (07.06.2017).

Comisión Europea. Libro Blanco sobre el futuro de Europa. Reflexiones y escenarios para la UE en 2025 (1 de marzo 2017).

Comisión Europea. COM (2016) 950 final Plan de Acción Europeo de la Defensa, Bruselas, (30.11.2016).

Dassù, Marta, Ischinger, Wolfgang, et al. «Keeping Europe Safe After Brexit». European Council of Foreign Relations, 20 de marzo 2018, (www .ecfr.eu).

De Castro Ruano, José Luis. «Las nuevas capacidades de la UE en materia de política exterior en el Tratado de Lisboa». Unión europea. Aranzadi, n. ${ }^{\circ} 10$ (2009).

De Castro Ruano, José Luis. «La Unión Europea y la gestión de crisis: entre las potencialidades del Tratado de Lisboa y la falta de voluntad de los Estados: Libia como evidencia». En El arreglo pacífico de controversias internacionales, Eva M. Vázquez Gómez, M. Dolores Adam Muñoz y Noé Cornago Prieto (Coords.). Valencia: Tirant lo Blanch, 2013.

De Castro Ruano, José Luis. «La evolución de la Unión Europea como actor en materia de seguridad y defensa. En busca de un relanzamiento siempre pendiente». Cuadernos Europeos de Deusto, n. ${ }^{\circ}$ especial, octubre, (2015). 
De Castro Ruano, José Luis. «La Política Europea de Seguridad y Defensa (PESD) y la evolución de las relaciones transatlánticas en el contexto de la crisis de Irak». Cursos de Derecho Internacional y Relaciones Internacionales de Vitoria-Gasteiz, 2004. Leioa, Servicio Editorial de la UPV/EHU, 2005.

Decisión 2017/2315/PESC del Consejo, de 11 de diciembre de 2017, por la que se establece una cooperación estructurada permanente y se fija la lista de Estados miembros participantes. (DO, L 331, de 14.12.2017).

García Pérez, Rafael. «Las misiones PESD como instrumento de la política exterior de la UE». En Cursos de Derecho Internacional y relaciones Internacionales de Vitoria-Gasteiz 2009. Leioa: Servicio Editorial de la UPV/EHU, 2010.

González Alonso, Luis Norberto. «¿Obligación jurídica o mero compromiso político?: la cláusula de solidaridad». Revista General de Derecho Europeo, n. ${ }^{\circ} 12$ (2007) (www.iustel.com).

Gros-Verheyde, Nicolas. «Huit pays adhérent á 1'initiative européenne d'intervention d'E. Macron. La lettre d'intention signée». Bruxelles2 Pro, 25 junio 2018(https: //club.bruxelles2eu)

Gros-Verheyde, Nicolas. «Trump tâcle le projet Macron d’armée européenne. A-t-il raison?». Bruxelles2 Pro, noviembre 2018 (http: //www.bruxellees2.eu).

Gros-Verheyde, Nicolas. «L'initiative européenne d’intervention». Bruxelles2, 18 junio 2018 (https: //club.bruxelles2.eu).

Gros-Verheyde, Nicolas. «Trump tâcle le projet Macron d’armée européenne. A-t-il raison?». Bruxelles2 Pro, noviembre 2018 (http: //www.bruxellees2.eu).

Gros-Verheyde, Nicolas. «Give PESCO a chance» en Bruselles Pro, Décembre, 2017 (www.bruxelles2.eu/2017/12/give-pesco-a-chance/).

Informe del Parlamento Europeo. The Cost of Non-Europe in Common Security and Defence Policy, Bruselas, 2013.

Juncker, Jean C. Estado de la Unión 2018. La hora de la soberanía europea (12 de septiembre de 2018).

Juncker, Jean C. Discurso sobre el Estado de la Unión «Hacia una Europa Mejor: una Europa que proteja, empodere y vele por la seguridad (14 de septiembre de 2016)

Liñán Nogueras, Diego. «Un nuevo discurso estratégico para la política exterior de la Unión Europea». Revista de Derecho Comunitario Europeo, n. 56 (2017): (DOI: https://doi.org/10.18042/cepc/rdce.56.01)

López-Jacoiste, Eugenia; «La nueva Cooperación Estructurada Permanente: ¿impulso definitivo para una verdadera PCSD en Europa?». Anuario Español de Derecho Internacional, n. ${ }^{\circ} 34$ (2018): 1075-1097 (DOI: 10.15581/010.34.10751097).

Moguerini, Federica. Doc. Consejo 10715/16, Estrategia Global sobre Política Exterior y de Seguridad de la Unión Europea: una visión común, una actuación conjunta: una Europa más fuerte (28.06.2016)

Montoya Cerio, Fernando. «Brexit, ficción o realidad: impacto sobre la PCSD de la UE». Documento Opinión del Instituto Español de Estudios Estratégicos, n. ${ }^{\circ} 64$ bis (2016), 24 de junio de 2016 (www.ieee.es).

Ortega Carcelén, Martín; «La Política Exterior y de Seguridad Común en el Tratado de Lisboa: un cauce adecuado a la espera de contenidos». Cuadernos Europeos de Deusto, n. 40 (2009). 
Roldán Barbero, Javier. «La Europa de la defensa pasa a la ofensiva». Revista General de Derecho Europeo, n. 43 (2017).

Sanahuja, José A.; Verdes-Montenegro, Francisco J.; «Estrategias de seguridad y desarrollo: discursos securitarios en la Unión Europea, Estados Unidos y España». En Derechos humanos y seguridad internacional: amenazas e involución. Anuario 2017-2018, Manuela Mesa (Coord.). Madrid: CEIPAZ, 2018.

Tamames, Jorge. «¿Es la democracia iliberal un problema?». Estudios de Política Exterior, 18 de abril de 2018 (https://politicaexterior.com).

Uribe Otalora, Ainhoa. La Política de Seguridad y Defensa de la Unión Europea. Las misiones en el exterior. Valencia: Tirant lo Blanch, 2014.

Urrea Corres, Mariola. «La Política Común de Seguridad y Defensa en el Tratado de Lisboa: la eficacia como objetivo, la flexibilidad como instrumento y la ambición como propuesta». Revista Española de Derecho Europeo, n. 33 (2010).

Védrin, Hubert. «The issue: When is it right to oust a tyrant? My veredict: in Libya it was justified but it's an unsoung precrecedent». Europe's World, Autumn (2011) (www .europesworld.org).

Wagner, Wolfgang y Anholt, Rosanne. «Resilience as the EU Global Strategy's new leitmotif: pragmatic, problematic or promising?». Contemporary Security Policy, n. 37 (2016): 414-430 (DOI: https://doi.org/10.1080/13523260.2016 .1228034)

Youngs, Richard. Europe's Decline and Fall: The Struggle Against Global Irrelevance. London: Profile Books, 2010.

Zakaria, Fareed. El futuro de la libertad: las democracias «iliberales» en el mundo. Madrid: Taurus, 2003.

\section{Sobre los autores}

José Luis DE CASTRO RUANO, Profesor Titular de Relaciones Internacionales de la Universidad del País Vasco/Euskal Herriko Unibertsitatea y Cátedra Jean Monnet de la Comisión Europea. Codirector de los Cursos de Derecho Internacional y Relaciones Internacionales de Vitoria-Gasteiz. Premio Extraordinario de Doctorado en Ciencias Sociales y Jurídicas 19921993; y VI Premio de Investigación «Francisco Javier de Landaburu.Universitas 2007». Últimas publicaciones: «The EU’s comprehensive approach as an alternative strategic framework for a security provider: the case of EU NAVFOR Somalia»; Global Affairs, Vol. 2, n. ${ }^{\circ}$ 2, 2016, pp. 177-186 (coautor con BORRAJO, D.). DOI: 10.1080/23340460.2016.1178459

ÁLVAREZ RUBIO, J.J., DE CASTRO RUANO, J.L.; Y SOROETA LICERAS, J. (Codirectores); Cursos de Derecho Internacional y Relaciones Internacionales de Vitoria-Gasteiz 2017. Pamplona, Aranzadi, 2018.

«La desinformación como instrumento político en la Sociedad Internacional actual: las respuestas desde la Unión Europea»; Revista Aranzadi Unión Europea, n. ${ }^{\circ}$ 7, 2018, pp. 25-38 (ISSN: 1579-0452) 
«Hacia una Unión Europea de la Defensa o cómo hacer de la necesidad virtud»; Anuario Español de Derecho Internacional, n. ${ }^{\circ}$ 34, 2018, DOI: 10.15581/010.34.1045-1073 (ISBN: 0212-0747)

«The European security agenda in the fight against terrorism»; MARRERO ROCHA, M. and TRUJILLO MENDOZA, H. (eds.). Jihadism, Foreign Fighters and Radicalization in the EU. Legal, Functional and Psychosocial Responses. London and New York, Routledge, 2019, pp. 113-130 (ISBN: 978-1-138-60442-1)

Diego BORRAJO VALIÑA es Doctor en Relaciones Internacionales (mencióninternacional) por la Universidad del País Vasco/Euskal Herriko Unibertsitatea (UPV/EHU), Posgrado en Estudios Internacionales en UPV/ EHU y Licenciado en Ciencias Políticas por la Universidad de Santiago de Compostela (USC). Ha sido investigador doctoral visitante en el Centre d'Études Européennes - Université Catholique de Louvain. Actualmente, sus líneas de investigación engloban el proceso de integración europea, los estudios críticos de seguridad y la teoría de las Relaciones Internacionales. Sus publicaciones son: «The EU's comprehensive approach as an alternative strategic framework for a security provider: the case of EU NAVFOR Somalia», Global Affairs, Vol. 2, n. ${ }^{\circ} 2$, 2016, pp. 177-186 (coautor con DE CASTRO RUANO, J.L.). DOI: 10.1080/23340460.2016.1178459; «El papel del enfoque integral como modelo de seguridad diferenciado para la Unión Europea: ¿un nuevo modelo de la Unión para las operaciones de paz interregionales en África?» en España y la Unión Europea en el orden internacional, Valencia, Tirant-lo-Blanch (2017): 995-1006.

\section{About the Authors}

José Luis DE CASTRO RUANO, Professor of International Relations at the University of the Basque Country (UPV/EHU), Jean Monnet Chair of the European Commission. Co-director of International Law and International Relations of Vitoria-Gasteiz Courses; Extraordinary Doctoral Award in Social and Legal Sciences 1992-1993; VI Research Prize «Francisco Javier de Landaburu.Universitas 2007». Recent Publications: «The EU's comprehensive approach as an alternative strategic framework for a security provider: the case of EU NAVFOR Somalia»; Global Affairs, Vol. 2, n. ${ }^{\circ}$ 2, 2016, pp. 177-186 (co-author con BORRAJO, D.). DOI: 10.1080/23340460.2016.1178459

ÁLVAREZ RUBIO, J.J., DE CASTRO RUANO, J.L.; Y SOROETA LICERAS, J. (Co-directors); Cursos de Derecho Internacional y Relaciones Internacionales de Vitoria-Gasteiz 2017. Pamplona, Aranzadi, 2018. 
«La desinformación como instrumento político en la Sociedad Internacional actual: las respuestas desde la Unión Europea»; Revista Aranzadi Unión Europea, n. ${ }^{\circ}$ 7, 2018, pp. 25-38 (ISSN: 1579-0452)

«Hacia una Unión Europea de la Defensa o cómo hacer de la necesidad virtud»; Anuario Español de Derecho Internacional, n. ${ }^{\circ}$ 34, 2018, DOI: 10.15581/010.34.1045-1073 (ISBN: 0212-0747)

«The European security agenda in the fight against terrorism»; MARRERO ROCHA, M. and TRUJILLO MENDOZA, H. (eds.). Jihadism, Foreign Fighters and Radicalization in the EU. Legal, Functional and Psychosocial Responses. London and New York, Routledge, 2019, pp. 113130 (ISBN: 978-1-138-60442-1)

Diego BORRAJO VALIÑA is a PhD in International Relations (international mention) at the University of the Basque Country (UPV/ EHU), Postgraduate in International Studies (UPV/EHU) and BA in Political Science at the University of Santiago de Compostela (USC). He has been a visiting doctoral researcher at the Centre d'Études Européennes - Université Catholique de Louvain. His main work-lines cover areas such as European integracion, critical security studies and international relations theory. His recent publications are: «The EU's comprehensive approach as an alternative strategic framework for a security provider: the case of EU NAVFOR Somalia», Global Affairs, Vol. 2, n..$^{\circ}$, 2016, pp. 177-186 (co-author con DE CASTRO RUANO, J.L.). DOI: 10.1080/23340460.2016.1178459; «El papel del enfoque integral como modelo de seguridad diferenciado para la Unión Europea: ¿un nuevo modelo de la Unión para las operaciones de paz interregionales en África?» en España y la Unión Europea en el orden internacional, Valencia, Tirantlo-Blanch (2017): 995-1006. 


\section{Derechos de autor}

Los derechos de autor (para la distribución, comunicación pública, reproducción e inclusión en bases de datos de indexación y repositorios institucionales) de esta publicación (Cuadernos Europeos de Deusto, CED) pertenecen a la editorial Universidad de Deusto. El acceso al contenido digital de cualquier número de Cuadernos Europeos de Deusto es gratuito inmediatamente después de su publicación. Los trabajos podrán leerse, descargarse, copiar y difundir en cualquier medio sin fines comerciales y según lo previsto por la ley; sin la previa autorización de la Editorial (Universidad de Deusto) o el autor. Así mismo, los trabajos editados en CED pueden ser publicados con posterioridad en otros medios o revistas, siempre que el autor indique con claridad y en la primera nota a pie de página que el trabajo se publicó por primera vez en CED, con indicación del número, año, páginas y DOI (si procede). Cualquier otro uso de su contenido en cualquier medio o formato, ahora conocido o desarrollado en el futuro, requiere el permiso previo por escrito del titular de los derechos de autor.

\section{Copyright}

Copyright (for distribution, public communication, reproduction and inclusion in indexation databases and institutional repositories) of this publication (Cuadernos Europeos de Deusto, CED) belongs to the publisher University of Deusto. Access to the digital content of any Issue of Cuadernos Europeos de Deusto is free upon its publication. The content can be read, downloaded, copied, and distributed freely in any medium only for non-commercial purposes and in accordance with any applicable copyright legislation, without prior permission from the copyright holder (University of Deusto) or the author. Thus, the content of CED can be subsequently published in other media or journals, as long as the author clearly indicates in the first footnote that the work was published in CED for the first time, indicating the Issue number, year, pages, and DOI (if applicable). Any other use of its content in any medium or format, now known or developed in the future, requires prior written permission of the copyright holder. 